\title{
Tendo que se adaptar a uma realidade incontestável e inesperada: ser portadora do HPV
}

\author{
Having to adapt to an unexpected and undeniable reality: being an HPV-infected patient \\ Teniendo que adaptarse a una realidad inesperada e innegable: ser portadora de VPH
}

\author{
Octavio Muniz da Costa Vargens ${ }^{\text {; }}$ Carla Marins Silva ${ }^{I I}$
}

\begin{abstract}
RESUMO: Pesquisa descritiva, qualitativa, cujo objetivo foi analisar o processo de interação da mulher com o diagnóstico de infecção pelo Papilomavírus Humano (HPV) no contexto de rastreamento para câncer do colo do útero. Realizada em 13 comunidades dos municípios de Duque de Caxias e Nova Iguaçu, no Estado do Rio de Janeiro, Brasil, entre 2006 e 2008. Os participantes foram 20 mulheres que tiveram diagnóstico de infecção pelo HPV dos tipos relacionados ao alto risco oncogênico, pelo método de captura híbrida. Para coleta de dados, utilizou-se a entrevista semiestruturada. A análise baseou-se nos pressupostos do Interacionismo Simbólico e da Grounded Theory. Os resultados evidenciaram a importante esfera de interação consigo mesma, na qual predomina o significado de ter que lidar com uma realidade incontestável determinada pelo fato de ser portadora do HPV. Para as mulheres, esta é uma doença que era até então desconhecida e que lhes impõe mudanças na vida inesperadas e difíceis de aceitar.
\end{abstract}

Palavras-Chave: Enfermagem; câncer de colo do útero; HPV; interacionismo simbólico; saúde da mulher.

ABSTRACT: This is a descriptive piece of research, with qualitative approach, which aimed at analyzing the interaction process of women with the diagnosis of Human Papilomavirus (HPV) infection in the context of screening for cervical cancer. The research was conducted in 13 communities in the municipalities of Duque de Caxias and Nova Iguaçu, Rio de Janeiro State, Brazil, from 2006 to 2008. Research participants were 20 women diagnosed with HPV infection related to high oncogenic risk by hybrid capture. Semi-structured interviews were used for data collection. Symbolic Interactionism and Grounded Theory frameworks guided data collection and analysis. Results showed the important sphere of self-interaction, in which predominant significance lies on having to cope with an unquestionable reality determined by the HPV-infection condition. To those women, that disease imposes unexpected changes in life which are hard to cope with.

Keywords: Nursing; cervical cancer; HPV; symbolic interaction; women's health.

RESUMEN: Investigación descriptiva, cualitativa, que objetivó analizar el proceso de interacción de las mujeres con el diagnóstico de la infección por Papiulomavirus Humano (VPH) en el contexto de la detección del cáncer de cuello uterino. Realizada en 13 comunidades en los municipios de Duque de Caxias y Nova Iguaçu, Río de Janeiro, Brazil, entre 2006 y 2008. Las participantes fueron 20 mujeres con diagnóstico de la infección por VPH de alto riesgo oncogénico por la captura híbrida. Para la recolección de datos se utilizó una entrevista semi-estructurada. El análisis se basó en el Interaccionismo Simbólico y la Grounded Theory. Los resultados revelaron una importante esfera de la interacción con sí misma, en la cual predomina la importancia de tener que lidiar con una realidad incuestionable determinada por el hecho de ser portadora de VPH. Para estas mujeres, esta es una enfermedad que, hasta entonces desconocida, impone cambios inesperados en la vida y difíciles de aceptar.

Palabras Clave: Enfermería; cáncer de cuello uterino; VPH; interacción simbólica; salud de la mujer.

\section{INTRODUÇÃO}

O câncer do colo do útero permanece como uma importante causa de morbidade e mortalidade na população feminina em todo mundo, embora possa ser curado se detectado precocemente. De acordo com as últimas estimativas mundiais para o ano de 2012, o câncer de colo do útero é o quarto tipo de câncer mais comum entre as mulheres, com 527 casos novos. Vale lembrar que sua incidência é maior em países menos desenvolvidos ${ }^{1}$.
No Brasil, Estimativas do Instituto Nacional do Câncer (INCA), indicam que, em 2014, podem ocorrer cerca de 15.590 casos novos, o que equivale a um risco estimado de 15,33 casos a cada 100.000 mulheres ${ }^{1}$.

O exame citopatológico (Papanicolaou) é o método utilizado para o rastreamento das lesões precursoras do câncer do colo do útero. No caso de resultado anormal a mulher participa de um processo

IEnfermeiro Obstetra, Doutor. Professor Titular da Faculdade de Enfermagem da Universidade do Estado do Rio de Janeiro. Brasil. E-mail: omcvargens@uol.com.br

IIEnfermeira Obstétrica, Doutora. Professora Adjunta da Faculdade de Enfermagem da Universidade do Estado do Rio de Janeiro. Brasil. E-mail: carlamarinss@hotmail.com

IIIPesquisa desenvolvida com apoio financeiro do Conselho Nacional de Desenvolvimento Científico e Tecnológico, CNPq. 
para confirmação diagnóstica que implica na repetição do exame citopatológico, realização de exame colposcópico e de biópsia, se indicados ${ }^{2}$.

Nas últimas décadas, a infecção pelo papilomavírus humano (HPV) por tipos de alto risco oncogênico tem sido reconhecida como uma causa necessária para desenvolvimento do câncer do colo do útero ${ }^{3-7}$. O HPV é transmitido por via sexual, mas a infecção geralmente é assintomática e transitória. No entanto, algumas mulheres desenvolvem infecções persistentes, que podem resultar em lesões precursoras do câncer do colo do útero ${ }^{8}$.

Em 2003, o Food and Drug Administration (FDA), aprovou o teste de captura híbrida de segunda geração (DNA do HPV) para uso no rastreamento do câncer do colo do útero em conjunto com o exame citopatológico 9 . Diversos estudos observaram que este teste é sensível para detectar lesão precursora de alto grau ou câncer do que o exame de Papanicolaou ${ }^{10-15}$. Ele tem a vantagem de ser um teste com leitura objetiva e automatizada, e a coleta pode ser feita pela própria mulher, uma alternativa que permite aumentar a cobertura do exame em regiões de difícil acesso ou com características culturais que levem à resistência na realização do exame ginecológico. O teste de captura híbrida para HPV é comercializado no mercado brasileiro, sendo disponibilizado por vários planos de saúde, e a sua incorporação no Sistema Único de Saúde (SUS) está em processo de discussão.

A utilização do teste de HPV como estratégia de rastreamento para câncer do colo do útero implica em comunicar a uma grande proporção de mulheres que elas são portadoras de uma infecção sexualmente transmissível que causa câncer. Apesar da maioria das mulheres portadoras de HPV não necessitar de procedimento diagnóstico mais agressivo (biópsia) é possível que este diagnóstico tenha algum tipo de repercussão na sua vida social e conjugal.

Um resultado anormal pode causar ansiedade e medo, e para muitas mulheres o conceito de lesão precursora pode ser difícil de compreender, levando a suposição de ter ou estar em risco de ter um câncer estabelecido. Existem poucos estudos que abordam este tema, em geral o enfoque está na identificação dos fatores relacionados à adesão ao rastreamento.

Em 2002, o Instituto Nacional do Câncer (INCA) realizou um estudo para avaliar a acurácia desta nova tecnologia. Este estudo verificou que entre as 2.059 mulheres estudadas, 264 (12,8\%) apresentaram infecção HPV por tipos de alto risco oncogênico, destas, $32(12,1 \%)$ tiveram diagnóstico confirmado para lesão de alto grau ou câncer ${ }^{15}$.

Foi o resultado deste estudo que indicou a necessidade de estudar o mesmo fenômeno sob outra perspectiva, levando-nos a optar por estudo qualitativo. Assim, o objeto desta pesquisa foi o processo de interação da mulher com o diagnóstico de infecção pelo HPV no contexto de rastreamento para câncer do colo do útero.
Considerando que o significado é construído no interior do indivíduo a partir de um processo de interação social e expressa a síntese conceitual e prática das dimensões políticas e sociais ${ }^{16}$, compreender e interpretar o significado atribuído pela mulher ao diagnóstico de HPV é uma ferramenta fundamental para o planejamento e avaliação das ações de saúde. Assim, neste estudo ${ }^{\mathrm{III}}$, o objetivo foi analisar o processo de interação da mulher com o diagnóstico de infecção pelo HPV no contexto de rastreamento para câncer do colo do útero.

A enfermagem brasileira vem demonstrando cada vez mais preocupação com as questões relativas ao câncer e às doenças de transmissão sexual, por considerar que estas aparecem como causas importantes no perfil de morbimortalidade entre mulheres, e por constituírem agravos à saúde evitáveis através de ações básicas e implementação de políticas públicas viáveis em nosso país. Deve-se levar em conta também que, via de regra, nos programas de atenção básica à saúde, cabe à enfermagem importante papel como educadora e formadora de hábitos de vida saudáveis, por ser este grupo profissional aquele que mantém contato mais próximo com os usuários dos serviços de saúde.

Este estudo contribui para a discussão das políticas de prevenção e controle desta neoplasia, uma vez que oportuniza a compreensão das relações de interação social da mulher na situação de portadora da infecção pelo HPV, a partir do significado atribuído por ela a este diagnóstico num contexto de rastreamento para câncer do colo do útero.

\section{Referencial Teórico-Metodológico}

Trata-se de pesquisa descritiva com abordagem qualitativa, considerando a natureza subjetiva do objeto de estudo, e sua característica de buscar a visão do todo tendo como base as vivências dos atores sociais envolvidos no processo ${ }^{17}$.

Realizou-se em 13 comunidades dos municípios de Duque de Caxias e de Nova Iguaçu, no Estado do Rio de Janeiro, no período de outubro/2006 a setembro/2008. A escolha deste cenário se deu em função da ocorrência da infecção pelo HPV em mulheres que ali habitam e que tiveram acesso ao exame de captura híbrida para rastreamento de Câncer de Colo do Útero, no ano de $2002^{15}$.

As participantes da pesquisa foram selecionadas entre as mulheres que participaram de estudo anterior $^{15}$ e tiveram diagnóstico de infecção pelo HPV dos tipos relacionados ao alto risco oncogênico, através do método de captura híbrida.

Tal composição dos grupos, no decorrer do estudo, deu-se com base no proposto para o processo de análise comparativa constante, característica da Grouded Theory ${ }^{18}$. O quantitativo total de mulheres entrevistadas foi de 20 , atendendo ao critério da saturação teórica ${ }^{19}$. 
Como estratégia de coleta de dados, utilizou-se a entrevista semiestruturada, o que permitiu ao entrevistador servir-se de um guia de tópicos para garantir que todas as áreas das questões fossem cobertas ${ }^{17}$. Como ponto de partida para as entrevistas optou-se por uma pergunta sobre significado atribuído pela mulher ao diagnóstico de infecção pelo HPV no contexto de rastreamento para câncer do colo do útero. As entrevistas foram gravadas em equipamento $m p 3$ tendo sido transcritas na íntegra para análise.

O processo de análise dos dados baseou-se nos pressupostos teórico-metodológicos do Interacionismo Simbólico ${ }^{16}$ e da Grounded Theory ${ }^{18}$. De acordo com estes pressupostos, a análise comparativa constante dos dados indica quais novos grupos amostrais devem ser incluídos e, dessa forma, que novos conjuntos de dados devem ser obtidos. Por esse método há um ir e vir entre a coleta e a análise, em que as informações são analisadas sistemática e simultaneamente à coleta ${ }^{20}$. $O$ processo coleta/ análise ocorreu nas seguintes etapas:

- transcrição das entrevistas e sua distribuição vertical, etapa em que os discursos foram separados linha por linha e colocados em quadros específicos;

- codificação aberta ou codificação substantiva, realizada com todos os dados após cada coleta. Estes foram analisados linha por linha e com a atribuição de códigos, mantendo-se os termos que foram utilizados pelos sujeitos do estudo;

- categorização provisória, em que os códigos substantivos foram agrupados observando-se as similaridades e diferenças conceituais. Nessa fase não foram considerados o assunto ou o tema tratado, apenas os conceitos relevantes que puderam ser entendidos como pertencentes a um mesmo fenômeno;

- codificação teórica ou categorização, momento em que, definidas as categorias emergentes dos dados, foram estabelecidas as inter-relações entre estas, consideradas suas subcategorias;

- codificação seletiva, quando há descrição do processo social básico, desencadeando a categoria central que é o elo entre todas as categorias ${ }^{21}$.

Em atendimento ao preconizado pela Resolução n ${ }^{\circ}$ 196/1996 do Conselho Nacional de Saúde ${ }^{22}$, de 10 de outubro de 1996, o Projeto foi submetido à apreciação do Comitê de Ética em Pesquisa da Universidade do Estado do Rio de Janeiro, sob protocolo $n^{\circ}$ 031/2007. Todos os sujeitos do estudo assinaram o Termo de Consentimento Livre e Esclarecido.

\section{Resultados e Discussão}

A análise dos dados evidenciou importante esfera de interação, que constituiu a categoria analítica central deste estudo: interagindo consigo mesma deparando-se com uma realidade incontestável.

\section{Interagindo consigo mesma - deparando-se com uma realidade incontestável}

Descobrir-se portadora do HPV na relação consigo mesma significou para a mulher ter de lidar com a dura realidade do diagnóstico e, por conseqüência, ter de adaptar-se a esta nova realidade. Assim, constituíram-se as duas dimensões desta categoria: Vivendo o impacto do diagnóstico e Adaptando-se à realidade do diagnóstico.

\section{Vivendo o impacto do diagnóstico}

No processo de interação consigo mesma a partir do diagnóstico do HPV, a mulher se vê diante de uma realidade que lhe é imposta e com a qual, inevitavelmente, tem que lidar. É caracterizado como um processo que oscila entre a dúvida, angústia e a incredulidade por um lado, e a esperança, o otimismo e a crença por outro.

Na hora eu fiquei espantada, [...] Quando eles mandaram, ah, você tem que ir não sei o que no INCA, não o que. Ih! Será que eu estou com doença ruim? Você tem que rir para resolver logo isso. O que que eu tenho que fazer lá? para ver se deu algum problema, se deu algum problema, tem que ir lá no INCA. O que que é isso? Não estou com doença ruim nem nada, mas aí, depois que eu fui lá, eu fiquei mais tranquila. (E3)

Olha, eu levei um susto, queria saber como foi que aconteceu isso, eu fiz mil perguntas para mim mesma, sem nenhuma resposta, como eu [...] consegui adquirir essa doença, como eu peguei. Aí eu falei, será que vou ter cura? Fiquei deprimida, não queria nem ir para o hospital, mas com o apoio da minha família, acredito que vou conseguir ficar boa. (E2)

Esta oscilação tem incorporada a idéia dos diferentes mecanismos de defesa habitualmente usados pelos indivíduos diante de situações estressoras.

Viver o impacto do diagnóstico significou, para estas mulheres, o choque relacionado com o fato de descobrir-se portadora de uma doença desconhecida (choque com o desconhecido) e por conta disso, viver os sentimentos ou situações que caracterizam o medo do desconhecido.

A primeira reação foi expressa pela ideia do susto. Estas mulheres se viram assustadas pelo fato de receberem o diagnóstico.

Olha, eu levei um susto, queria saber como foi que aconteceu isso. (E4)

Fiquei com medo, assustada [...] fiquei com medo, me subiu aquela quentura [...]. (E2)

Passado o susto inicial, a mulher se vê não acreditando que possa ser realidade, que ela seja portadora do HPV. Analisa sua vida, seu comportamento, e quanto mais o faz, mais tem convicção da impossibilidade de ser realmente infectada. 
O que é isso? Não estou com doença ruim nem nada. (E3)

Eu falei é impossível, eu não. [...], pois eu estou usando a camisinha. Eu só uso camisinha, não vou com ele sem camisinha. (E8)

Diante do diagnóstico desta condição inesperada e desconhecida surge a sensação de dúvida quanto ao que seja a doença, se e como esta irá interferir em sua vida. Além disso, ainda tem dificuldade de entender o que as pessoas falam.

Eu perguntei assim: o que é isso, HPV? Como eu peguei isso? Agora eu não sei porque eu tenho capacidade de pegar câncer mais cedo ou mais tarde [...]Ih!, será que eu estou com doença ruim? (E13)

[...] mas dentro da gente, lá dentro, como a gente vai cuidar? Se a gente vai ficar isolado, se o nosso marido vai aceitar isso [...] (E14)

Porque eu sou assim: às vezes, as pessoas falam para mim e eu não entendo. Se não falar direto, eu não entendo... (E12)

A infecção pelo HPV e, consequentemente, o câncer de colo de útero trazem um grande desafio para a saúde reprodutiva e sexual. Os dados epidemiológicos desvelam desdobramentos para a saúde reprodutiva que nem sempre são tratados em sua complexidade e abrangência. Nessa situação ainda está o desconhecimento acerca do vírus por parte da população feminina, que pode favorecer o desenvolvimento de concepções errôneas que podem interferir de forma negativa no comportamento da portadora de HPV ${ }^{23,24}$.

Para o Interacionismo Simbólico a sociedade é uma instituição composta por pessoas e grupos em constante interação. Esta interação tem como alicerce o compartilhamento de sentidos sob a forma de compreensões e expectativas comuns. Este processo interativo é dinâmico, variando de acordo com as diferentes situações que são enfrentadas. Estas situações são percebidas de forma seletiva, de acordo com as necessidades, que por sua vez são definidas a partir dos sentidos que as coisas têm para as pessoas, e que são derivadas da interação ${ }^{16}$.

Assim, no presente estudo, o diagnóstico de HPV significou para a mulher descobrir-se diante de uma realidade imposta e desconhecida, marcada pela vivência de sentimentos os quais tem influência direta na definição da situação em que se encontra e de sua linha ação visando a adaptação a esta nova realidade. Outros estudos com mulheres portadoras de HPV corroboram esta ideia e a vivência desses sentimentos diante desta nova realidade ${ }^{23,25}$.

Em meio a esse turbilhão ficou evidenciado que o sentimento de medo/susto aparece como diretamente relacionado com o impacto do diagnóstico. Vale lembrar que, frequentemente, ter o diagnóstico de uma doença pode desencadear uma série de reações emocionais. Em uma pesquisa sobre o diagnóstico de câncer de mama ${ }^{26}$, o autor mostra que o medo com o inesperado pode gerar a perda do equilíbrio emocional e da saúde.

No presente estudo, após este susto inicial, a mulher, ao definir a situação para si mesma ${ }^{16}$ analisa sua vida e seus comportamentos e nega a possibilidade de ser infectada pelo HPV. Esta negação pode ser entendida como forma de defesa, empregada por muitos indivíduos diante de situações difíceis. A negação é um mecanismo de defesa que pode ser manifestado pelo medo de enfrentamento da doença e até mesmo pelo medo da morte. As patologias de difícil diagnóstico ou estigmatizadas levam as pessoas a reprimirem as emoções e a negarem as situações por elas ${ }^{27}$.

Com a mulher que se descobre portadora de HPV ocorre dessa mesma maneira, particularmente pelo fato de se tratar de uma doença sexualmente transmissível.

\section{Adaptando-se à realidade imposta pelo diagnóstico}

A realidade do diagnóstico para as entrevistadas, após o impacto inicial do resultado, significou que estas teriam, de alguma forma, que lidar com esta situação. Neste momento a mulher define a situação para si mesma e busca de conhecimento e sentimentos, saídas, força de enfretamento para adaptação.

A mulher, em meio a este processo, sofre um turbilhão de emoções que a deixa fragilizada quando pensa na situação vivenciada.

Ai, quando eu penso nisso, eu fico nervosa, vou ficar chorando, vou ficar deprimida. Ai, teve um dia que eu cheguei em casa, comecei a chorar, chorar, chorar. (E2)

Com o HPV, eu lido com isso com um pouco de raiva... (E19)

Este processo é reforçado quando ela aplica experiências passadas, vivenciadas na família para tentar explicar sua situação, gerando esses depoimentos:

Nenhuma diferença (na vida), porque a maioria da minha família morre de câncer ou morre de coração. Quer dizer, já era de se esperar. (E15)

Será que vou ficar igual algumas pessoas da minha família que já têm tendência a câncer? [...] a gente fica assim, pensando assim, poxa, será que vou ficar igual minha tia? (E3)

Como forma de se livrar da doença busca tirar o útero de forma imediata para evitar consequências piores, mas se sente impotente por não poder decidir sobre seu corpo.

[...] tanto que eu queria tirar tudo, tirar o útero, tirar tudo, eu não quero ter mais filho, no caso, quem tivesse 
essa... o corpo é meu, eu decido com ele o que eu quiser, muitas mulheres pensam assim. Quem sabe do corpo da gente é a gente. Se eu pudesse tirar, na época que falaram para mim que eu tinha HPV, eu tinha tirado. [...] só que a minha ginecologista não deixou. [Disse] que não é assim, que tem que passar por um monte de coisas, teste psicológico... (E5)

Primeira oportunidade que me der eu tiro meu útero, [...]. (E17)

No processo de adaptação a mulher seleciona todos os aspectos positivos para seu conforto. Com isso, acredita que a doença não muda nada em sua vida.

Não, não mudou não, só na hora que eu fiquei espantada, né? (E3)

A busca pela a compreensão do que seja a doença se torna um fator importante na promoção do alívio nesta mulher.

Mas aí, depois que eu fui lá, eu fiquei mais tranquila (E9)

Aí eles falaram para mim que com o tempo some, [...]. Não esquentei minha cabeça. (E3)

Quando ela me disse isso, o resultado, eu fiquei mais aliviada. (E7)

Com isso, torna-se otimista considerando o futuro de maneira positiva.

Normal, eu sou uma pessoa que não penso negativo, tudo que eu faço eu penso positiva. Minha mãe ficou apavorada, meu marido, mas eu... Eles estavam apavorados, eu não, eu sabia que não tinha nada. (E1)

$\mathrm{O}$ apoio espiritual também contribui para o quadro de otimismo e esperança, o que dá às mulheres a certeza de cura.

Mas aí, comecei a orar, orar, vou ter que reagir, eu acredito que vou ser curada (E2)

Então eu fiquei assim, vamos ter orações mesmo, pedir cuidado a Deus e vou cuidando daqui para frente. (E4)

Deixa para lá, entrego na mão de Deus. (E5)

No processo de adaptação à realidade imposta pelo diagnóstico de HPV, as mulheres apresentam reações emocionais como medo, preocupação e tristeza. Outro estudo com mulheres portadoras de HPV confirmam elas ficam fragilizadas com essa nova situação ${ }^{25}$.

Nesse momento, a mulher aplica experiências passadas, vivenciadas no âmbito familiar, o que corrobora este processo. A visão de mundo de um indivíduo é construída em seu ambiente social, a partir do que ele observa, capta, analisa e armazena. Em seu cotidiano o indivíduo observa situações parecidas e recebe conhecimentos entre diferentes gerações no convívio familiar ${ }^{23}$.

De acordo com as premissas do Interacionismo Simbólico, o ser humano age em relação às coisas com base nos sentidos que tais coisas têm para ele.
Entende-se por essas coisas os objetos físicos, seres humanos, instituições, ideias, ações humanas e outras situações vividas no cotidiano do indivíduo. O sentido das coisas é proveniente da interação social que o indivíduo estabelece com os outros. Estes sentidos são manipulados e modificados através de um processo interpretativo, usado pela pessoa ao se relacionar com as coisas e situações que ela encontra ${ }^{16}$.

A partir desse momento, o indivíduo considera o futuro, olha a si mesmo na situação. Logo em seguida, determina a linha de ação em relação aos objetos, incluindo outros indivíduos ${ }^{28}$.

Assim, nesta pesquisa, a mulher deseja enfrentar a situação imposta e manifesta a vontade de resolução. Entretanto, tem sensação de impotência por não poder decidir sobre seu corpo, seu destino. Os profissionais de saúde passam a se apropriar do corpo da pessoa adoecida e a destituem do poder de decidir sobre seu tratamento. Em um outro estudo, com mulheres mastectomizadas, essa sensação de impotência também apareceu mostrando a impossibilidade de mudar o seu destino.

Nesse período de adaptação, as mulheres, neste estudo, relatam que, apesar de tudo, acreditam que a doença não mudará nada em sua vida. Este sentimento de indiferença pode ser atribuído ao desconhecimento da doença ou à não assimilação adequada do valor atribuído a esse vírus ${ }^{29}$.

A partir daí, a mulher seleciona todos os aspectos positivos para seu conforto. Um deles é a busca pelo conhecimento. Em outro estudo, as mulheres portadoras de HPV entrevistadas relataram que vivenciaram momentos angustiantes até receberem a devida orientação a respeito da doença ${ }^{23}$.

Assim, a mulher passa a ficar mais otimista em relação ao seu futuro. Outro estudo corrobora esta ideia de que a contaminação pelo vírus proporcionou reflexão e a busca de um comportamento favorável à saúde. E uma das estratégias de enfrentamento que são utilizadas pelas participantes deste estudo foi o apoio espiritual. Ao se deparar com uma situação de doença ou morte, uma das formas de enfrentamento está relacionada diretamente com as maneiras de expressão de espiritualidade pela fé e pelas crenças religiosas ${ }^{30}$.

\section{Conclusão}

Os resultados evidenciaram que a esfera de interação consigo mesma é dividida em duas dimensões: Vivendo o impacto do diagnóstico e Adaptando-se à realidade do diagnóstico, nas quais predomina o significado de ter que lidar com uma realidade incontestável determinada pelo fato de ser portadora do HPV. Para estas mulheres essa é uma doença até então desconhecida que lhes impõe mudanças na vida, inesperadas e difíceis de aceitar. 


\section{REFERÊNCIAS}

1.Ministério da Saúde (Br). Instituto Nacional de Câncer José Alencar Gomes da Silva. Coordenação de Prevenção e Vigilância (Brasil). Estimativa 2014: Incidência de Câncer no Brasil. Rio de Janeiro: INCA; 2014.

2.Ministério da Saúde (Br). Secretaria de Atenção a Saúde. Departamento de Atenção Básica. Controle dos cânceres do colo do útero e da mama. 2a ed. Brasília (DF): Editora do MS; 2013.

3.International Agency for Research on Cancer. IARC Monographs on the evaluation of carcinogenic risks to humans. Paris(Fr): IARC; 1995.

4.Walboomers JMM, Jacobs MV, Manos MM, Bosch FX, Kummer JA, Shah KV, et al. Human papillomavirus is a necessary cause of invasive cervical cancer worldwide. J Pathol. 1999; 189(1): 12-9.

5.Franco EL, Rohan TE, Villa LL. Epidemiologic evidence and human papillomavirus infection as a necessary cause of cervical cancer. J Natl Cancer Inst. 1999; 91:506-11. 6.Bosch FX, Lorincz A, Muñoz N, Meijer CJLM, Shah $\mathrm{KV}$. The casual relation between human papillomavirus and cervical cancer. J Clin Pathol. 2002; 55: 244-65.

7.Franco EL, Harper DM. Vaccination againt human papillomavirus infection: a new paradigm in cervical cancer control. Vaccine. 2005; 23:2388-94.

8.International Agency for Research on Cancer. IARC confirms efficacy of cervix cancer screening for women 25-65 in reducing mortality. Paris (Fr): IARC; 2004.

9.Food and Drug Administration [Site de Internet]. FDA Approves Expanded Use of HPV Test. [cited in 2014 May 20] Disposible in: http://www.fda.gov/ohrms/ dockets/dockets/07p0210/07p-0210-ccp0001-01-FDANews-vol3.pdf.

10.Cuzick J, Beverley E, Ho L, Terry G, Sapper H, Mielzynska I, et al. HPV testing in primary screening of older women. Br J Cancer. 1999; 81: 554-8.

11.Ratman S, Franco EL, Ferenczy A. Human papillomavirus testing for primary screening of cervical cancer precursors. Cancer Epidemiol Biomarkers Prev. 2000; 9: 945-51. 12.Blumenthal PD, Gaffikin L, Chirenje ZM, McGrath J, Womack S, Shah K. Adjunctive testing for cervical cancer in low resource settings with visual inspection, HPV, and the Pap smear. Int J Gynecol Obstet. 2001; 72: 47-53.

13.Kulasingam SL, Hughes JP, Kiviat NB, Mao C, Weiss NS, Kuypers JM, Koutsky LA. Evaluation of hum pappilomavirus testing in primary screening for cervical abnormalities: comparison of sensitivity, specificity, and frequency of refferal. JAMA. 2002; 288: 1749-57.

14.Salmerón J, Lazcano-Ponce E, Lorincz A, Hernandez M, Hernandez P, Leyya A, et al. Comparision of HPVbased assays with Papanicolaou smears for cervical cancer screening in Morelos State, Mexico. Cancer Causes Control. 2003; 14: 505-12.

15.Girianelli VR, Thuler LCS, Szklo M, Donato A, Zardo LM, Lozana JA, et al. Comparision of HPV DNA tests and liquid based cytology with conventional cytology for the early detection of cervix uteri cancer. Eur J Cancer Prev. 2006; 15:504-10.

16.Blumer H. Symbolic Interacionism: perspective and method. London(UK): University of California Press; 1969.

17.Polit DF, Beck CT, Hungler BP. Pesquisa em enfermagem: métodos, avaliação e utilização. $5^{\mathrm{a}}$ ed. Porto Alegre (RS): Artmed; 2004.

18.Glaser BG, Strauss AL. The discovery of grounded theory: strategies for qualitative research. New York: Aldine de Gruyter; 1967.

19.Glaser BG. Theoretical sensitivity: advances in the methodology of grounded theory. Mill Valley (USA): Socilogy Press; 1978.

20.Stern PN. Grounded Theory methodology: its uses and processes. Image. 1980; 12(1):20-3.

21.Kimura AF, Tsunechiro MA, Ângelo M. Teoria Fundamentada nos Dados. In: Merighi MAB, Praça NS. Abordagens teórico-metodológicas qualitativas: a vivência da mulher no período reprodutivo. Rio de Janeiro: Guanabara Koogan; 2003. p. 39-45.

22.Conselho Nacional de Saúde (Br). Resolução n ${ }^{\circ}$ 196, de 10 de outubro de 1996: Diretrizes e normas regulamentadoras de pesquisas envolvendo seres humanos. Brasília (DF): CNS; 1997. [citado em 10 jul 2012]. Disponível em: http:/conselho.saude.gov.br/comissao/ conep/resolucao.html.

23.Sousa LB, Pinheiro AKB, Barroso MGT. Ser mulher portadora do HPV: uma abordagem cultural. 2008; 42:737-43.

24. Oliveira AS, Lima TM, Campos FC, Bezerra KC, Oriá $\mathrm{MOB}$, Damasceno AKC. Avaliação da prevalência de infecções genitais em gestantes atendidas em consulta de enfermagem ginecológica Rev enferm UERJ. 2013; 21:228-33 25.Veloso LC, Silva AC, Silva CLLB. HPV: percepção das portadoras em relação ao diagnóstico da doença. $\mathrm{R}$ Interd. 2013; 6(4):1-10.

26.Funghetto SS, Terra MG, Wolff LR. Mulher portadora de câncer de mama: percepção sobre a doença, família e sociedade. Rev Bras Enferm. 2003; 56:528-32.

27.Gracioli MAS, Leopardi MT, Gonzales RMB. Assistência de enfermagem a mulheres mastectomizadas com bases nos conceitos e pressupostos de Joyce Travelbee. In: Costenaro RGS. Cuidando em enfermagem: da teoria a prática. Rio Grande do Sul: Unifra; 2003. p.121-65.

28.Charon JM. Symbolic Interactionism. 2a ed. Englewood Cliffs (USA): Prentice Hall; 1985.

29. Carvalho ALS, Barros SKS, Leitão NMA, Nobre RNS, Bezerra SJS, Pinheiro AKB. Sentimentos vivenciados por mulheres submetidas a tratamento para papillomavírus humano. Esc Anna Nery. 2007; 11:248-53.

30.Trentini M, Silva SH, Valle ML, Hammerschmidt KSA. Enfrentamento de situações adversas e favoráveis por pessoas idosas em condições crônicas de saúde. Rev Latina-Am Enfermagem. 2005; 13:38-45. 